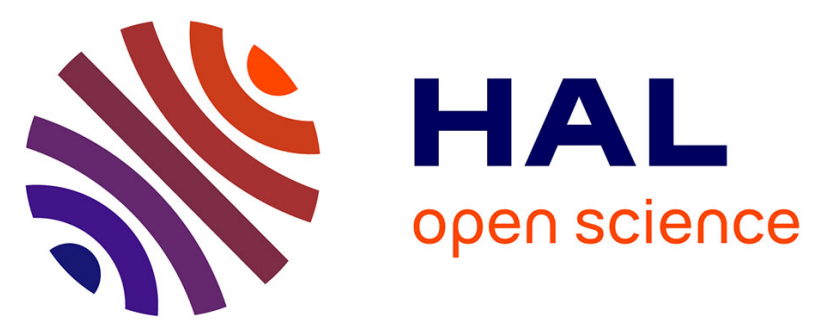

\title{
New insights into the reactivity of detonation nanodiamonds during the first stages of graphitization
}

Florent Ducrozet, Hugues Girard, Jocelyne Leroy, Eric Larquet, Ileana Florea, Emilie Brun, Cécile Sicard-Roselli, Jean-Charles Arnault

\section{- To cite this version:}

Florent Ducrozet, Hugues Girard, Jocelyne Leroy, Eric Larquet, Ileana Florea, et al.. New insights into the reactivity of detonation nanodiamonds during the first stages of graphitization. Nanomaterials, 2021, 11 (10), pp.2671. 10.3390/nano11102671 . cea-03379043

\section{HAL Id: cea-03379043}

https: / hal-cea.archives-ouvertes.fr/cea-03379043

Submitted on 14 Oct 2021

HAL is a multi-disciplinary open access archive for the deposit and dissemination of scientific research documents, whether they are published or not. The documents may come from teaching and research institutions in France or abroad, or from public or private research centers.
L'archive ouverte pluridisciplinaire HAL, est destinée au dépôt et à la diffusion de documents scientifiques de niveau recherche, publiés ou non, émanant des établissements d'enseignement et de recherche français ou étrangers, des laboratoires publics ou privés.

\section{(c)(1)}

Distributed under a Creative Commons Attribution| 4.0 International License 
Article

\title{
New Insights into the Reactivity of Detonation Nanodiamonds during the First Stages of Graphitization
}

\author{
Florent Ducrozet 1,2, Hugues A. Girard 1,*, Jocelyne Leroy ${ }^{1}$, Eric Larquet ${ }^{\text {, }}$, Ileana Florea ${ }^{4}$, Emilie Brun ${ }^{2}$, \\ Cécile Sicard-Roselli ${ }^{2}$ and Jean-Charles Arnault ${ }^{1, *}$
}

Citation: Ducrozet, F.; Girard, H.A Leroy, J.; Larquet, E.; Florea, I.;

Brun, E.; Sicard-Roselli, C.;

Arnault, J.-C. New Insights into the Reactivity of Detonation

Nanodiamonds during the First

Stages of Graphitization.

Nanomaterials 2021, 11, 2671.

https://doi.org/10.3390/

nano11102671

Academic Editor:

Christophe Donnet

Received: 23 September 2021

Accepted: 7 October 2021

Published: 11 October 2021

Publisher's Note: MDPI stays neutral with regard to jurisdictional claims in published maps and institutional affiliations.

Copyright: (C) 2021 by the authors. Licensee MDPI, Basel, Switzerland. This article is an open access article distributed under the terms and conditions of the Creative Commons Attribution (CC BY) license (https://creativecommons.org/license s/by/4.0/).
1 Université Paris-Saclay, CEA, CNRS, NIMBE, CEDEX, 91191 Gif sur Yvette, France; florent.ducrozet@cea.fr (F.D.); jocelyne.leroy@cea.fr (J.L.)

2 Institut de Chimie Physique, UMR 8000, CNRS, Université Paris-Saclay, Orsay 91405, France; emilie.brun@universite-paris-saclay.fr (E.B.); cecile.sicard@universite-paris-saclay.fr (C.S.-R.)

3 Condensed Matter Physics Laboratory (PMC), UMR CNRS 7643, Ecole Polytechnique, IP-Paris, 91228 Palaiseau, France; eric.larquet@polytechnique.edu

4 Laboratory of Physics of Interfaces and Thin Films (LPICM), UMR CNRS 7647, Ecole Polytechnique, IP-Paris, 91228 Palaiseau, France; lenuta-ileana.florea@polytechnique.edu

* Correspondence: hugues.girard@cea.fr (H.A.G.); jean-charles.arnault@cea.fr (J.-C.A.)

\begin{abstract}
The present study aims to compare the early stages of graphitization of the same DND source for two annealing atmospheres (primary vacuum, argon at atmospheric pressure) in an identical set-up. DND samples are finely characterized by a combination of complementary techniques (FTIR, Raman, XPS, HR-TEM) to highlight the induced modifications for temperature up to $1100{ }^{\circ} \mathrm{C}$. The annealing atmosphere has a significant impact on the graphitization kinetics with a higher fraction of $\mathrm{sp}^{2}-\mathrm{C}$ formed under vacuum compared to argon for the same temperature. Whatever the annealing atmosphere, carbon hydrogen bonds are created at the DND surface during annealing according to FTIR. A "nano effect", specific to the $<10 \mathrm{~nm}$ size of DND, exalts the extreme surface chemistry in XPS analysis. According to HR-TEM images, the graphitization is limited to the first outer shell even for DND annealed at $1100{ }^{\circ} \mathrm{C}$ under vacuum
\end{abstract}

Keywords: nanodiamonds; surface graphitization; X-ray photoelectron spectroscopy

\section{Introduction}

Since the last decade, diamond nanoparticle or nanodiamond (ND) has been the object of a growing interest from researchers, engineers, and companies. Indeed, ND gather the outstanding physical and chemical properties of the bulk diamond and new assets conferred by the nanoscale. Among the different ND sources, nanodiamonds produced by detonation (DND) are actively investigated, mainly for bioapplications, catalysis, novel lubricants, and composites [1-4]. For instance, DND are widely used as vectors for delivery of drugs or genetic material [5,6] for their $<10 \mathrm{~nm}$ diameter provides a high specific surface area (up to $400 \mathrm{~m}^{2} / \mathrm{g}$ ) and allows to expect renal clearance [7]. Their carbon-related surface chemistry plays a central role as it greatly influences the surface charge of DND for an efficient electrostatic loading of biomolecules of interest [8], and it strongly drives their colloidal properties governing interactions with solvents [9]. Apart from its biomedical applications, this versatile surface chemistry also offers optimized chemical bonding possibilities with oils or polymer matrix toward novel lubricants and composites materials, thereby maximizing the expected mechanical, electrical, or thermal properties. Furthermore, surface chemistry also drives DND surface-related properties such as (photo)catalytic abilities [10,11], radiosensitization [12,13], and radicals overproduction [14] or antibacterial behavior [15]. 
For all these applications, if oxidized and hydrogenated surfaces have already been widely investigated, graphitized surfaces may also be promising and yet intricate. As shown by Lin et al. [16], the graphitization state of DND strongly drives their catalytic behavior, as the $\mathrm{sp}^{2} / \mathrm{sp}^{3}$ interface may offer favorable electron transfer routes if carefully designed. The formation of a sp2-organized surface covering an $\mathrm{sp}^{3}$ core may have promising properties conferred by fullerene or graphene assets such as photothermal therapy [17]. Optimized functionalization routes were also developed on graphitized DND, via arylation reactions, for instance, to graft complex organic moieties for bioapplications or polymer composites [18].

The formation of fully graphitized DND up to onion-like carbon (OLC) structures from DND is now well documented. Indeed, as OLC have promising applications for energy storage, catalysis, and composites $[19,20]$, the formation of OLC from ND has been extensively investigated [21]. This approach allows the creation of high-purity material and small sizes at low cost. The full transformation of ND into OLC structures was thus studied experimentally by annealing at temperatures included between $1100{ }^{\circ} \mathrm{C}$ and $1900{ }^{\circ} \mathrm{C}$ under different atmospheres (vacuum [22], argon [23], helium [24], nitrogen [25], hydrogen [26]). In parallel, formations of curved graphite-like structures and concentric-shells fullerenes on nanodiamonds were theoretically investigated [27-29]. In this context, a few years ago, Zeiger et al. published a complete review on OLC synthesis and energy storage applications that includes the current state of the art on graphitization mechanisms of ND [21]. According to previous investigations, thermal effects induce first the desorption of water molecules and then one of the different oxygen functional groups present at ND surface (hydroxyl, ether, carbonyl, carboxyl, anhydride, lactone). Consequently, dangling bonds are created on $\mathrm{sp}^{3}$-carbon atoms from the DND surface that can either be saturated by species or molecules present in the annealing atmosphere or combined together to form $\mathrm{sp}^{2}$ carbon local bonds. The surface graphitization seems to also be initiated from the non-diamond carbon present at the ND surface within the $700-800{ }^{\circ} \mathrm{C}$ temperature range. The reorganization of the complete first outer shell of ND as a carbon onion shell occurs for higher annealing temperatures, typically in the $900-1100{ }^{\circ} \mathrm{C}$ range. However, the primary steps of $\mathrm{sp}^{3}-\mathrm{C}$ to $\mathrm{sp}^{2}-\mathrm{C}$ transition at the DND's surface remain less understood and finally only few studies have really focused on the first stages of graphitization under vacuum [18,30-34]. Furthermore, from the best of our knowledge, in such studies, the impact of the annealing atmosphere on the early stages of graphitization mechanisms of DND was not investigated in detail.

The present study aims to compare the early stages of graphitization of the same DND source for two different annealing atmospheres (primary vacuum and argon at atmospheric pressure) in an identical set-up. All DND samples are finely characterized by a combination of complementary techniques to highlight the induced modifications for temperature up to $1100{ }^{\circ} \mathrm{C}$. FTIR and XPS investigations allow probing the effects on the surface chemistry, whereas Raman and HR-TEM observations evidence the evolution of the carbon hybridization and of the crystalline structure versus the annealing temperature for each atmosphere. The sensitivity of each technique to $\mathrm{sp}^{2}$ carbon is compared. We show that the annealing atmosphere has an impact on the graphitization kinetics. Whatever the annealing atmosphere, carbon hydrogen bonds are created at the DND surface during annealing according to FTIR, and the origin of the involved hydrogen species is discussed. Furthermore, we also evidence a "nano effect" on XPS analysis which exalts the extreme surface chemistry, specific to the $<10 \mathrm{~nm}$ size of DND. 


\section{Materials and Methods}

\subsection{Nanodiamond Powder}

Detonation nanodiamonds (DND) were purchased from Adamas Nanotechnologies (ND5nmN, carboxylated, Raleigh, NC, USA). This initial particle will be referred here as "initial DND". TEM observations allowed the measurement of the Feret diameter considering 170 particles; it was centered around $6 \mathrm{~nm}$.

\subsection{Annealing under Vacuum}

Annealing treatments of DND were realized in a tubular furnace of Carbolite Gero company (Sheffield, UK). A quartz tube was filled with $60 \mathrm{mg}$ of initial ND in the center and inserted in the middle of the furnace. The tube was connected to a primary pumping $\left(\approx 10^{-3}\right.$ mbar). Vacuum was achieved and maintained for $10 \mathrm{~min}$ before any annealing treatment to favor the desorption of water and impurities. Annealing was then performed at temperatures from 800 to $1100{ }^{\circ} \mathrm{C}$ for $4 \mathrm{~h}$ while maintaining pumping. The temperature ramp for heating was maintained around $70^{\circ} \mathrm{C} / \mathrm{min}$.

\subsection{Annealing under Argon}

Annealing under argon atmosphere (99.9997\% purity) was realized with the same equipment at atmospheric pressure. The tube was connected to argon with a 20 SCCM flux. The tube was first heated to $300{ }^{\circ} \mathrm{C}$ for $20 \mathrm{~min}$ to allow the desorption of water and impurities to avoid a pre-pumping step. Annealing was then performed at temperatures from 800 to $950{ }^{\circ} \mathrm{C}$ for $4 \mathrm{~h}$. Temperatures were controlled with a type $\mathrm{K}$ thermocouple introduced in the furnace. The measured accuracy on expected temperatures was \pm 1.5 ${ }^{\circ} \mathrm{C}$. The temperature ramp for the heating periods was maintained at around $70{ }^{\circ} \mathrm{C} / \mathrm{min}$.

\subsection{Homogenization of Annealed DND in Water}

To allow their analysis in a reproducible manner, the DND were homogenized in water just after annealing. Annealed powders were collected in a $15 \mathrm{~mL}$ plastic tube and $3 \mathrm{~mL}$ of ultrapure water $(18.2 \mathrm{M} \Omega . \mathrm{cm})$ were added. Homogenization of the powder was obtained by a sonication step of $30 \mathrm{~min}$ with a $1 \mathrm{~s}$ on/off period and an amplitude of $60 \%$ (Cup Horn Bioblock Scientific 750 W, equipped with a cooling system, Illkirch-Graffenstaden, France).

\subsection{Fourier Transform Infrared (FTIR) Measurements}

Infrared spectra were recorded with a Bruker Vertex 70 spectrometer equipped with a diamond ATR system (Billerica, Massachusetts, USA). A measure of $2 \mu \mathrm{L}$ of DND in water were deposited and dried on the ATR crystal (MIRacle, PIKE Technologies, Fitchburg, WI, USA) before analysis. Acquisition represents the average of 64 scans recorded with a $4 \mathrm{~cm}^{-1}$ resolution at room temperature and ambient atmosphere with a nitrogen-cooled MCT detector. A break was applied in the 2280-2400 $\mathrm{cm}^{-1}$ region to avoid the contribution of atmospheric $\mathrm{CO}_{2}$ absorption bands. A baseline correction was applied for analyses of DND annealed at 900 and $950{ }^{\circ} \mathrm{C}$ under vacuum.

\subsection{X-Ray Photoelectron Spectroscopy (XPS) Analysis}

A measure of $10 \mu \mathrm{L}$ of DND in water was deposited on a silicon substrate covered by a gold coating made by evaporation to limit the charge phenomenon during analysis. The substrates were dried and then analyzed. XPS measurements were performed on a Kratos Analytical Axis Ultra DLD spectrometer equipped with a monochromated Al K $\alpha$ $(1486.6 \mathrm{eV}) \mathrm{X}$-ray source and a charge compensation system (Manchester, UK). The take-off angle was set at $90^{\circ}$ relative to the sample surface. Spectra were acquired at a pass energy of $160 \mathrm{eV}$ for the survey, $40 \mathrm{eV}$ for core levels (O 1s, N 1s, C 1s, Zr 3d). C 1s spectra shown in this study were acquired at $10 \mathrm{eV}$ to reach a higher energy resolution. 
Binding energies were referenced to the $A u 4 f_{7 / 2}$ peak located at $84 \mathrm{eV}$. After the background subtraction by a Shirley correction, a curve fitting procedure was carried out to extract the components of the $\mathrm{C} 1 \mathrm{~s}$ core level using Voigt functions with a Lorentzian to Gaussian ratio of $30 \%$. For the component of $\mathrm{sp}^{2}$ carbon, an asymmetry factor was added.

\subsection{Raman Analysis}

Raman spectra were recorded with a Horiba Xplora spectrometer equipped with a $532 \mathrm{~nm}$ laser with a $0.79 \mathrm{~mW}$ power (Kyoto, Japan). $10 \mu \mathrm{L}$ of DND in water were deposited on a silicon substrate and dried. Each spectrum is the average of 3 acquisitions realized at different positions on the substrate. The acquisition time is one minute, cumulated 10 times.

\subsection{Thermogravimetric Analysis (TGA)}

TGA measurements under vacuum and argon atmosphere were realized with a Netzsch STA 449 C (Selb, Germany). An alumina crucible filled with about $3 \mathrm{mg}$ of initial particles was used for each analysis. Analysis was performed from 23 to $1100{ }^{\circ} \mathrm{C}$ with a 20 ${ }^{\circ} \mathrm{C} / \mathrm{min}$ heating and a $20 \mathrm{~mL} / \mathrm{min}$ argon flux.

\subsection{High-Resolution Transmission Electron Microscopy (HR-TEM) Observations}

Transmission electron microscopy (TEM) was performed on a Thermo Fisher Scientific $^{\mathrm{TM}}$ G3 Titan Themis 300 transmission electron microscope (C-Twin objective lens: $\mathrm{Cs}=$ $2.7 \mathrm{~mm}, \mathrm{Cc}=2.7 \mathrm{~mm}$, Focal length $=3.5 \mathrm{~mm}$, Waltham, MA, USA) operating at $300 \mathrm{kV}$ accelerating voltage. Prior to the observation, the DND were deposited on a $3 \mathrm{~mm}$ diameter copper grid covered with a holey carbon film. To analyze the impact of the annealing conditions on the morphological and structural characteristics of the samples, HR-TEM observations were performed at 520.000× magnification for different defocus values using low dose mode on a Falcon3 EC 4k/4k Direct Detection Electron (DDE) camera. In order to best preserve samples from electron beam irradiation during image acquisition, a total electron dose of $25 \mathrm{e}^{-} / \AA^{2}$ was used for a limited exposure time of $1 \mathrm{~s}$.

\section{Results}

Thermogravimetric analysis (TGA) was first performed on initial DND under argon atmosphere at atmospheric pressure to determine the desorption thresholds of adsorbed water and oxygen functional groups (Figure 1). As expected, two main mass drops can be observed, well evidenced by the derivative function. The first one, which corresponds to the release of free, loosely, and tightly bound water [35], occurs between $100{ }^{\circ} \mathrm{C}$ and $200{ }^{\circ} \mathrm{C}$, while the second mass drop, located between $500{ }^{\circ} \mathrm{C}$ and $700{ }^{\circ} \mathrm{C}$, corresponds to carbon-oxygen function removal at DND surface [35]. Beyond $800^{\circ} \mathrm{C}$, the decrease of the desorption rate points out that most of the carbon-oxygen functions should have been removed. This temperature then appears a pertinent one for starting our annealing thermal range. 


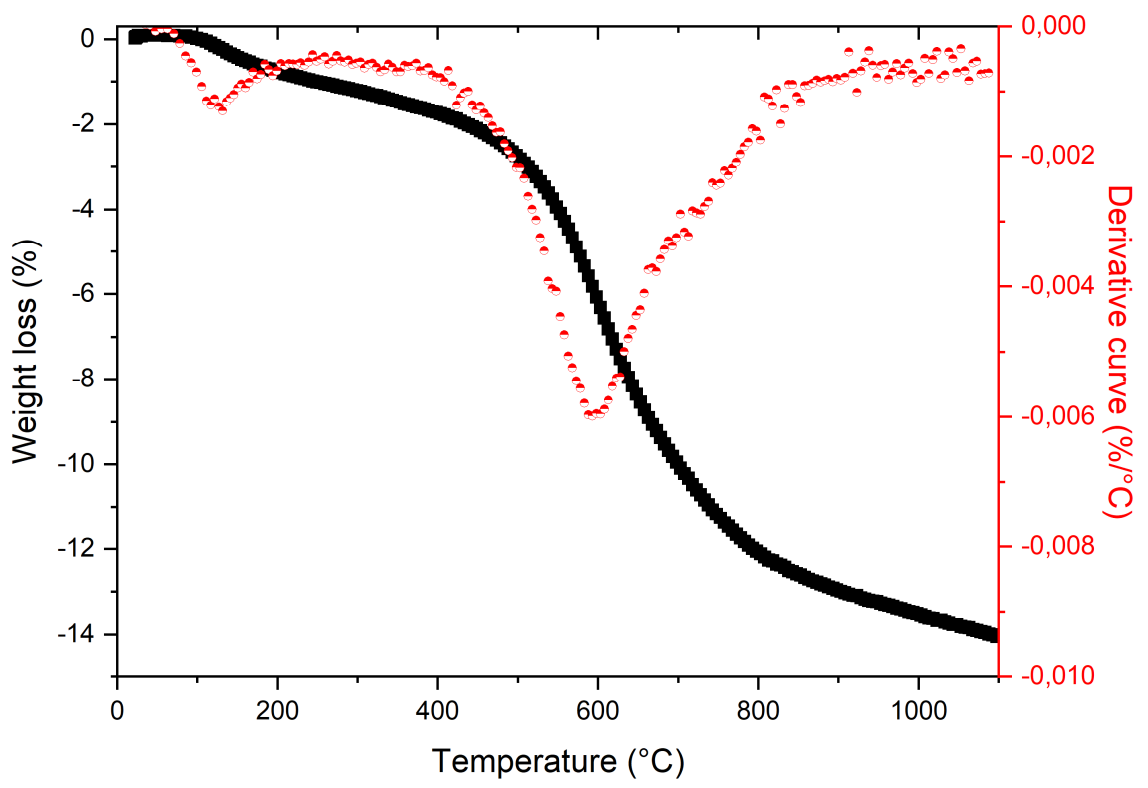

Figure 1. TGA spectra of initial DND annealed under argon atmosphere (black) and TGA derivative curve (red).

DND were then annealed in a tubular furnace during $4 \mathrm{~h}$ at $800,850,900$ and $950{ }^{\circ} \mathrm{C}$, under vacuum or argon atmospheres to monitor the surface modifications. Annealed samples were resuspended in water and a sonication step was realized to break and separate the biggest agglomerates. Each sample was then characterized by FTIR, XPS, Raman, and HR-TEM to probe and compare their inner and surface chemistry, their carbon hybridization, and their crystallographic structure and morphology.

The evolution of FTIR spectra from the initial DND to the annealed samples is depicted on Figure 2. For all samples, bands located at $3250 \mathrm{~cm}^{-1}$ and $1630 \mathrm{~cm}^{-1}$ due to O-H stretching and $\mathrm{O}-\mathrm{H}$ scissor bending modes may be partially or totally related to the presence of water molecules since ATR measurements were performed under air at ambient temperature. 


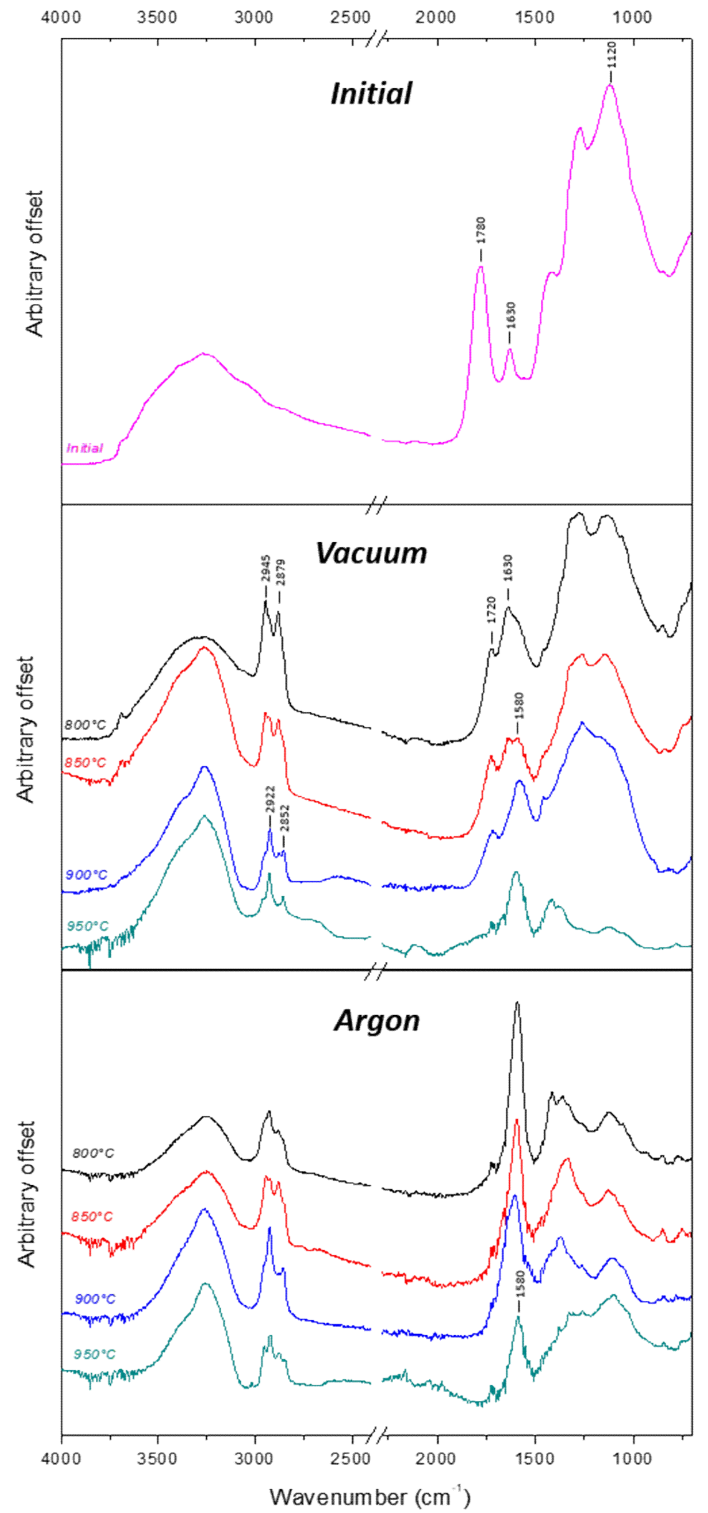

Figure 2. FTIR spectra of initial and annealed DND from $800{ }^{\circ} \mathrm{C}$ to $950{ }^{\circ} \mathrm{C}$ for both atmospheres.

The spectrum of the initial DND is characterized by a prominent $\mathrm{C}=\mathrm{O}$ carboxylic stretching band at $1780 \mathrm{~cm}^{-1}$ accompanied with another pronounced band around $1120 \mathrm{~cm}^{-1}$ related to single bounded carbon-oxygen groups such as etheric or alcoholic functions. This is in agreement with the specifications given by the DND manufacturer (ADAMAS), i.e., oxidized surface. The peak at $1630 \mathrm{~cm}^{-1}$ is assigned to O-H scissor bending frequency, which corresponds to hydroxyl groups involved in the carboxylic functions and atmospheric water. It can be noticed that there is no clear visible sign of $\mathrm{C}-\mathrm{H}$ stretching modes around $2800-2900 \mathrm{~cm}^{-1}$ [36].

For DND annealed under vacuum, the $\mathrm{C}=\mathrm{O}$ stretching band was red-shifted to $1720 \mathrm{~cm}^{-1}$, in closer agreement with the ketones and aldehydes wavenumber range [36] associated with a progressive reduction of its area along with the raise of the annealing temperature. At the same time, alcoholic and etheric related bands around $1120 \mathrm{~cm}^{-1}$ are still present, with reduced intensities, and vanish at $950{ }^{\circ} \mathrm{C}$. Annealing under vacuum also brings interesting new features on the FTIR spectra. Already present at $800{ }^{\circ} \mathrm{C}$ as a shoulder, a new band appeared around $1580 \mathrm{~cm}^{-1}$ and is clearly visible at $900{ }^{\circ} \mathrm{C}$. This 
band was previously assigned to $\mathrm{C}=\mathrm{C}$ bonds from benzene structures, which appeared after vacuum annealing realized at $750{ }^{\circ} \mathrm{C}[37,38]$. Nevertheless, another assignment was proposed by Petit et al. and Stehlik et al., who linked this band to red-shifted $\mathrm{OH}$ bending modes related to specific water interaction with the hydrophobic surface of the hydrogenated DND [38,39]. The origin of this band will be further discussed. For all samples annealed under vacuum, we also noticed an intensity increase of $\mathrm{C}-\mathrm{H}$ stretching modes. At $800{ }^{\circ} \mathrm{C}$ and $850{ }^{\circ} \mathrm{C}$, these bands are located at 2945 and $2879 \mathrm{~cm}^{-1}$. Surprisingly, these $\mathrm{C}-\mathrm{H}$ stretching modes exactly correspond to $\mathrm{C}-\mathrm{H}$ signatures of DND voluntary hydrogenated either by annealing or plasma treatments under $\mathrm{H}_{2}$, as reported in literature [40]. However, for annealing temperatures higher than $900{ }^{\circ} \mathrm{C}$, these bands underwent a red-shift to 2922 and $2852 \mathrm{~cm}^{-1}$.

For samples annealed under argon atmosphere, a similar evolution versus the temperature can be seen with a strong reduction of $\mathrm{C}=\mathrm{O}$ and $\mathrm{C}-\mathrm{O}$ bands up to an almost complete removal of $\mathrm{C}=\mathrm{O}$ stretching band at $1720 \mathrm{~cm}^{-1}$. Here as well, $\mathrm{C}-\mathrm{H}$ stretching bands appear from $800{ }^{\circ} \mathrm{C}$ (Figure 2), with a more balanced ratio between $\mathrm{CH}_{3}(2945$ and $\left.2879 \mathrm{~cm}^{-1}\right)$ and $\mathrm{CH}_{2}\left(2922\right.$ and $2852 \mathrm{~cm}^{-1}$ ) asymmetric and symmetric stretching modes from $800{ }^{\circ} \mathrm{C}$ to $950{ }^{\circ} \mathrm{C}$. For these particles, the band at $1580 \mathrm{~cm}^{-1}$ becomes prominent from $800{ }^{\circ} \mathrm{C}$. This is a significant difference compared to vacuum atmosphere.

Modifications of carbon hybridization induced by DND annealing were then probed by Raman spectroscopy (Figure 3).

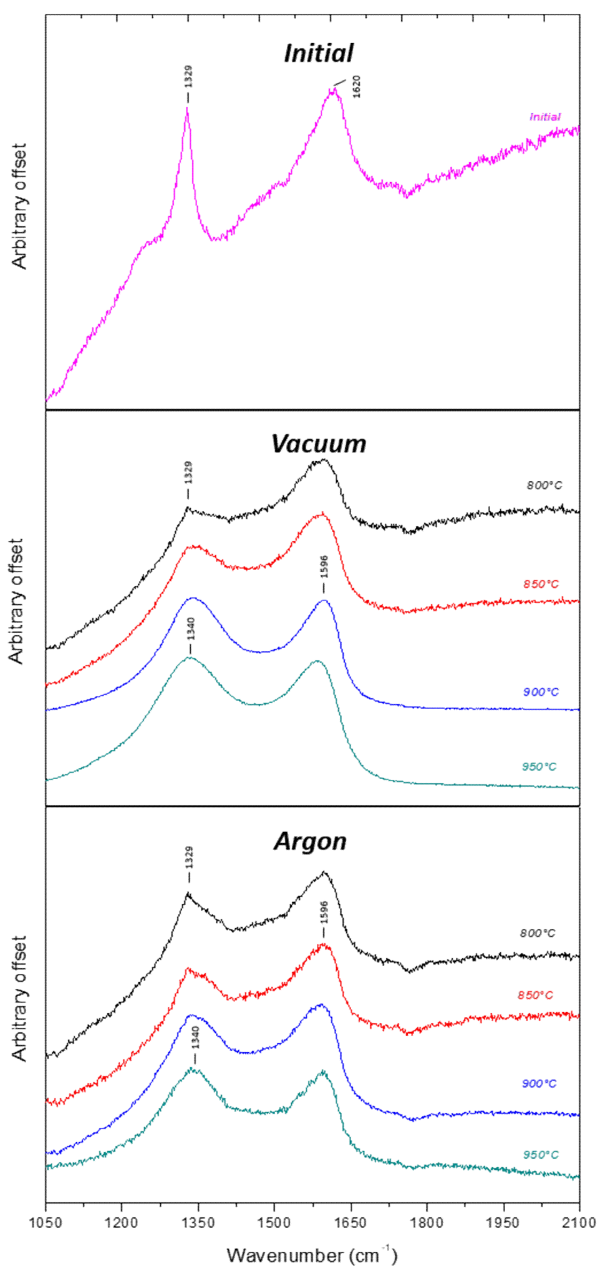

Figure 3. Raman spectra of initial and annealed DND from $800^{\circ} \mathrm{C}$ to $950{ }^{\circ} \mathrm{C}$ for both atmospheres. The excitation wavelength was $532 \mathrm{~nm}$. 
On the spectrum of initial DND, the first order peak of diamond, corresponding to the DND' core, lies at $1329 \mathrm{~cm}^{-1}$. It is red-shifted compared to bulk diamond due to the nanometric size of DND [41,42]. A broad peak centered around $1610 \mathrm{~cm}^{-1}$, usually named G-band, is in fact the superposition of at least three components ( $\mathrm{sp}^{2}$ carbon $1590 \mathrm{~cm}^{-1}$, $\mathrm{OH}$ - bending $1640 \mathrm{~cm}^{-1}, \mathrm{C}=\mathrm{O}$ - stretching $1740 \mathrm{~cm}^{-1}$ ) [40,42]. This $\mathrm{G}$ band is exalted in visible Raman analysis due to the intense scattering of $\mathrm{sp}^{2}$ bonded carbons compared to $\mathrm{sp}^{3}$ ones, by a factor of 50 [43]. On these initial DND, the $\mathrm{D}$ band corresponding to disordered carbon expected at $1340 \mathrm{~cm}^{-1}$ looks weak. The shape of the baseline also evidences a noticeable photoluminescence background arising from the sample. For vacuum, at the first annealing temperature, the diamond peak is still distinguishable but becomes no more visible for higher temperature treatment, being concealed in the D band at $1340 \mathrm{~cm}^{-1}$ that corresponds to disordered carbon. The contribution of oxidized functions is lowered in aid of the $G$ band that can clearly be seen with a maximum at 1596 $\mathrm{cm}^{-1}$. Under argon atmosphere, a similar evolution can be observed versus annealing temperature. The diamond peak remains detectable at $1329 \mathrm{~cm}^{-1}$ up to $850{ }^{\circ} \mathrm{C}$. To conclude, for both atmospheres, beyond $850{ }^{\circ} \mathrm{C}$, Raman spectroscopy performed with a green excitation reveals that a signature of a disordered carbon material has completely replaced the initial one. At the same time, we also noticed a vanishing of the photoluminescence background on these annealed samples.

To investigate the annealing consequences on atomic concentrations of each element present in the DND and on the carbon binding states, XPS analysis was performed on initial and annealed DND. A typical wide spectrum is shown on Figure 4a. The 4f peaks of gold originate from the substrate (see experimental part). In addition to photoemission peaks of carbon, nitrogen, and oxygen, the XPS analysis revealed the presence of zirconium. The corresponding atomic concentration is between 0.6 and 0.9 at. \%. The binding energy of $\mathrm{Zr} 3 \mathrm{~d}$ doublet corresponds to zirconium oxide [44]. Its origin is probably related to the deagglomeration milling process applied to DND that used zirconium oxide beads [45]. Therefore, the oxygen atomic concentrations provided in the following were corrected from the contribution of zirconium oxide assuming a stoichiometric zirconium oxide $\left(\mathrm{ZrO}_{2}\right)$.

For the initial DND, the oxygen and nitrogen atomic concentrations were 9.3 and 1.9 at. \%, respectively (Table 1). Oxygen arises from the different functional groups initially present at DND surface and from remaining adsorbed water, as shown by FTIR (Figure 2). The main nitrogen contribution measured by XPS is related to nitrogen atoms incorporated into the DND core during the detonation synthesis [46]. This is in agreement with literature where nitrogen concentrations up to 6 at. \% were measured by XPS for DND of different origins [47]. 


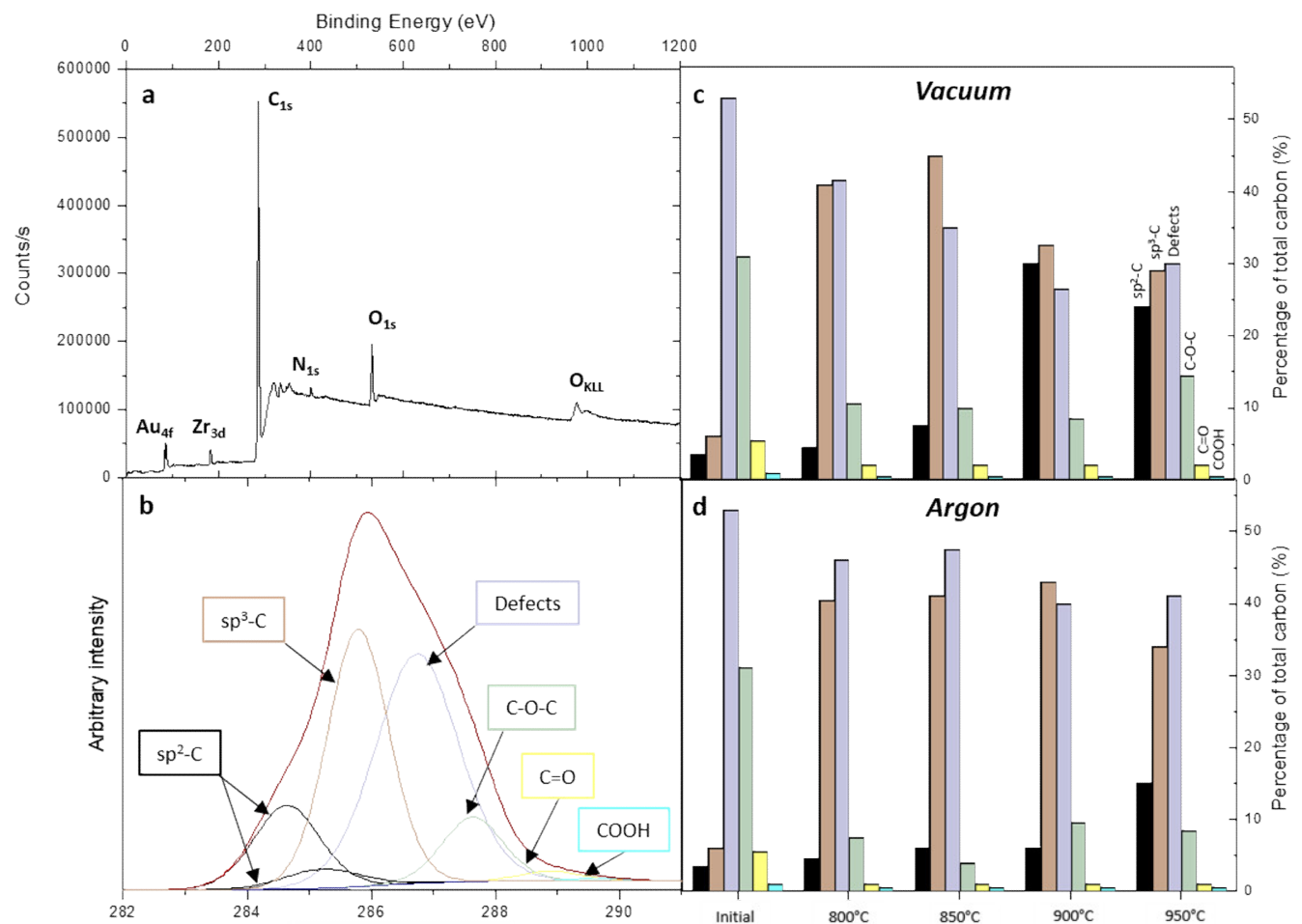

Figure 4. a) Wide XPS spectrum; b) typical C1s core level spectrum with fitting: DND after annealing at $950{ }^{\circ} \mathrm{C}$ under argon atmosphere; evolution of the six different components at $\mathrm{C} 1 \mathrm{~s}$ for initial and DND annealed under c) vacuum and d) argon atmospheres.

For DND annealed under vacuum, the oxygen concentration drops from 9.3 to 5.7 at. $\%$ after the first annealing at $800^{\circ} \mathrm{C}$. This appears to be in agreement with the TGA analysis (Figure 1) and FTIR spectroscopy (Figure 2). Then, the oxygen concentration remains almost stable for higher annealing temperatures (Table 1). This will be further discussed. For nitrogen, a decrease from 1.9 to 1.3 at. \% is obtained. Similar trends are measured for DND annealed under argon atmosphere, especially for nitrogen. Moreover, an even lower oxygen atomic concentration seems to be reached at high temperatures (3.6-4.0 at. \%).

Table 1. Oxygen and nitrogen atomic concentrations determined by XPS for initial and annealed DND for both atmospheres. The uncertainty on concentration is estimated to \pm 0.5 at $\%$.

\begin{tabular}{cccc}
\hline & Temperature $^{\circ} \mathbf{C}$ & Oxygen at. $\%$ & Nitrogen at. $\%$ \\
\hline Initial & & 9.3 & 1.9 \\
\hline \multirow{4}{*}{ Vacuum } & 800 & 5.7 & 1.6 \\
\cline { 2 - 4 } & 850 & 5.3 & 1.3 \\
\cline { 2 - 4 } & 900 & 6.1 & 1.2 \\
\cline { 2 - 4 } Argon & 950 & 5.2 & 1.3 \\
\cline { 2 - 4 } & 800 & 5.1 & 1.5 \\
\hline & 850 & 3.6 & 1.5 \\
\hline & 900 & 5.0 & 1.4 \\
\hline & 950 & 4.0 & 1.3 \\
\hline
\end{tabular}


In order to gain further insights into the carbon chemistry of annealed DND, systematic deconvolution of the $\mathrm{C} 1$ s core levels of each sample was performed. A typical C1s core level spectrum is presented on Figure $4 \mathrm{~b}$. Other fitted C1s core levels are provided in Supplementary Materials (Figure S1). It corresponds to DND annealed at $950^{\circ} \mathrm{C}$ under argon. After a background Shirley correction, different components have been considered to fit this spectrum. The $\mathrm{sp}^{3}$ carbon one at $285.4 \mathrm{eV}$ was taken as reference, reflecting intrinsic diamond. The component related to $\mathrm{sp}^{2}$ carbon is downshifted at $-1 \mathrm{eV}$ [48]. Its asymmetry, linked to its conductor character, was taken into account in the fit (Figure $4 b)$. With an upshift of $+1 \mathrm{eV}$ from $\mathrm{sp}^{3}$ carbon, a third component is assigned to take into account all carbon atoms not linked to an oxygen atom. This includes $\mathrm{sp}^{3} \mathrm{C}-\mathrm{C}$ neighboring structural defects commonly present in detonation ND, carbon partially saturated with hydrogen (at the surface and in the core of the particle) and carbon bounded to a nitrogen atom $[31,48]$. Components assigned to ether $(\mathrm{C}-\mathrm{O}-\mathrm{C}), \mathrm{C}=\mathrm{O}$, and carboxyl $(\mathrm{COOH})$ bonds are also present at higher binding energies, located, respectively, at +1.9 , +3 and $+4 \mathrm{eV}$ from $\mathrm{sp}^{3}$ carbon [49]. All C1s spectra were fitted using these six components. Percentages of total carbon for each component are reported on Figure $4 \mathrm{c}$, $\mathrm{d}$ for both annealing atmospheres. On initial DND, the component related to defective $\mathrm{sp}^{3} \mathrm{C}-\mathrm{C}, \mathrm{CH}_{\mathrm{x}}$ and $\mathrm{C}-\mathrm{N}$ bonds represents $53 \%$ of the total carbon at $\mathrm{C} 1 \mathrm{~s}$. Components linked to carbon-oxygen bonds are also preeminent, all together at $37 \%$. The $\mathrm{sp}^{3}-\mathrm{C}$ contribution is weak $(6 \%)$ while a small $\mathrm{sp}^{2}-\mathrm{C}$ is detected (3.5\%).

Whatever the annealing atmosphere, the $\mathrm{C} 1$ s spectrum undergoes strong modifications after the first annealing at $800{ }^{\circ} \mathrm{C}$. Indeed, the contributions of $\mathrm{C}-\mathrm{O}-\mathrm{C}, \mathrm{C}=\mathrm{O}$, and $\mathrm{COOH}$ bonds drop from $37 \%$ to $9 \%$ (argon) and 13\% (vacuum) of total carbon. Considering the stoichiometry of the different carbon-oxygen groups, this decrease is in good agreement with the decrease of the oxygen atomic concentration (Table 1) and FTIR observations, considering that adsorbed water may also participate to the oxygen content. The $\mathrm{sp}^{3}-\mathrm{C}$ contribution arises (40-41\%) and the component assigned to defects, $\mathrm{CH}_{x}$ and $\mathrm{C}-\mathrm{N}$ bonds is reduced ( $42 \%$ and $46 \%$ for vacuum and argon, respectively) though a slight increase of $\mathrm{sp}^{2}-\mathrm{C}$ is measured (4.5\%). A reorganization of the $\mathrm{C}-\mathrm{C}$ bonds seems to occur, which is more likely due to surface desorption of carbon-oxygen functions but can also be explained by a migration of vacancies contained in the diamond core up to the surface, as it is well known in the field of NV centers synthesis for such temperature [50].

For vacuum annealing, the $\mathrm{sp}^{2}-\mathrm{C}$ part is increasing to $7.5 \%$ at $850^{\circ} \mathrm{C}$, whereas it rises to $30 \%$ at $900{ }^{\circ} \mathrm{C}$. Regarding the part of defects, $\mathrm{CH}_{x}$ and $\mathrm{C}-\mathrm{N}$ bonds is further reduced to $35 \%$ and $26 \%$, respectively. The $\mathrm{sp}^{3}-\mathrm{C}$ contribution represents the major part of carbon at $45 \%$ for $850{ }^{\circ} \mathrm{C}$ while it decreases to $32 \%$ at $900{ }^{\circ} \mathrm{C}$. At higher temperatures, the sp ${ }^{2} \mathrm{C}$ and $\mathrm{sp}^{3}-\mathrm{C}$ are, respectively, 24 and $29 \%$. The component assigned to defects, $\mathrm{CH}_{\mathrm{x}}$ and $\mathrm{C}-\mathrm{N}$ bonds is $30 \%$.

Looking at C1s spectra, DND annealed under argon atmosphere underwent less modification for comparable temperatures. More specifically, a different trend for $\mathrm{sp}^{2}-\mathrm{C}$ versus temperature is observed. Indeed, this contribution remains low at $6 \%$ below 900 ${ }^{\circ} \mathrm{C}$. The part of $\mathrm{sp}^{2}-\mathrm{C}$ finally rises to $15 \%$ at $950{ }^{\circ} \mathrm{C}$. The part of defects, $\mathrm{CH}$ and $\mathrm{C}-\mathrm{N}$ bonds decreases from $48 \%$ to $40-41 \%$.

HR-TEM images were recorded to observe the impact of the annealing treatments on the DND morphology and crystalline structure (Figure 5). From the images, we can observe that the individual particles exhibit predominantly quasi-spherical shapes with diameters ranging from $2 \mathrm{~nm}$ to $8 \mathrm{~nm}$, with a mean size of $6 \mathrm{~nm}$. For the observed DND, different focalizations ( $\Delta \mathrm{f}$ range between $-70 \mathrm{~nm}$ to $-90 \mathrm{~nm}$ ) near the extended Scherzer defocus $(|1.2 \times \Delta \mathrm{fScherzer}|=87.5 \mathrm{~nm})$ were used on the same DND to maximize the phase contrast of a weak-phase object and resolution at the periphery of DND [51]. An example is presented in Figure $5 \mathrm{~d}$ for a DND annealed at $800{ }^{\circ} \mathrm{C}$ under vacuum. Indeed, near the extended Scherzer defocus (inset), the diamond (111) planes are observed, extending to the particle borders. Among DND annealed at $950{ }^{\circ} \mathrm{C}$ under the same atmosphere, if a part is affected by phase contrast (Figure 5e), other DND exhibit modified 
outer shells (Figure 5f). According to HR-TEM investigations, the crystalline diamond core of DND is preserved, whatever the annealing temperature for both atmospheres. The observed modifications (Figure 5f) only affect the first outer shells for the highest temperature under vacuum.

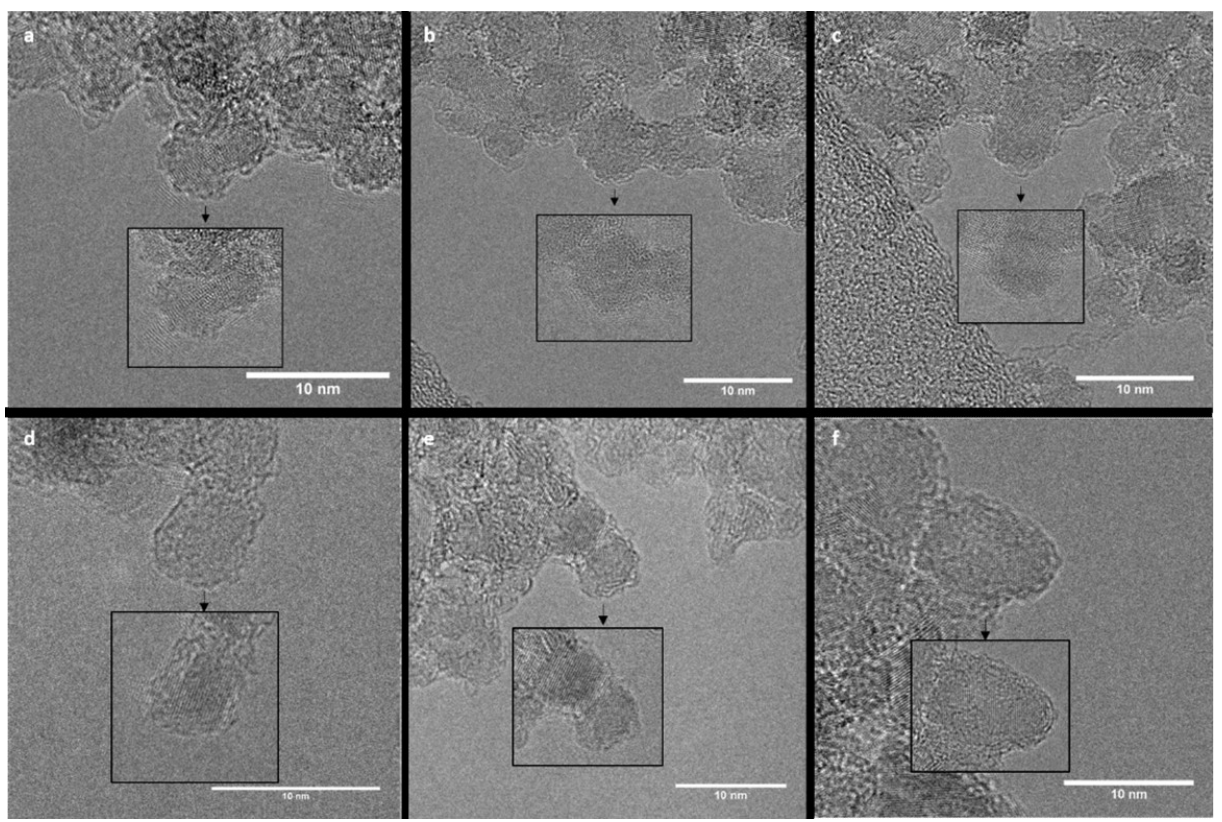

Figure 5. HR-TEM images of DND: a), b), and c) initial particles; d) $800{ }^{\circ} \mathrm{C} 4 \mathrm{~h}$; e) and f) $950{ }^{\circ} \mathrm{C} 4 \mathrm{~h}$. Images recorded near to Scherzer defocus are provided into insets.

\section{Discussion}

In the present study, chemical, structural, and morphological characterizations are combined to provide an accurate monitoring of the modifications underwent by detonation nanodiamonds during their annealing under a non-reactive atmosphere, i.e., vacuum or argon, from $800{ }^{\circ} \mathrm{C}$ up to $950{ }^{\circ} \mathrm{C}$. Our aim was to reveal how the superficial chemistry of DND evolves at the early stages of graphitization and before their transformation into OLC, with particular attention given to the nature of the surface terminations and carbon hybridization. This work exhibited a noticeable difference between both atmospheres of annealing, which will be discussed below.

We started our experiments with particles presenting an oxidized surface, as evidenced by the prominent carboxyl band in FTIR and the XPS atomic percentage of oxygen reaching almost 10 at. \%. In both conditions, from $800{ }^{\circ} \mathrm{C}$, annealing induced a strong modification of the oxidized terminations, revealed by the XPS atomic percentage of oxygen brought down to roughly 5 at. \% and the noticeable reduction and/or shift of the carbon-oxygen related IR absorption peaks. This remaining oxygen at the surface of our treated DND after annealing at $950{ }^{\circ} \mathrm{C}$ has to be discussed. Two options can be considered: (i) the impossibility to desorb certain kinds of carbon-oxygen groups even at $950{ }^{\circ} \mathrm{C}$ under vacuum or argon or (ii) a post-treatment spontaneous re-oxidation of the surface when exposed to air and/or dispersed in water. In the former case, persistence of carbon-oxygen functions above $800{ }^{\circ} \mathrm{C}$ will be only possible for carbonyl groups according to the literature [35,52]. This could explain the remaining of $\mathrm{C}=\mathrm{O}$ stretching band at $1720 \mathrm{~cm}^{-1}$ visible on FTIR spectra of vacuum annealed samples. Note that this band vanishes while the annealing temperature is increasing. Concerning single-bounded carbon-oxygen groups revealed by FTIR and XPS C1s core levels, their presence would rather be linked to a spontaneous re-oxidation of the annealed DND surface when being in contact with air atmosphere/water. Spontaneous interactions between diamond surface and water molecules were probed by HREELS [53]. Depending on the diamond surface 
chemistry, these investigations reveal the formation of $\mathrm{C}-\mathrm{O}$ and $\mathrm{C}=\mathrm{O}$ bonds for a non-hydrogenated diamond. Such re-oxidation mechanism may also arise from the reactivity of $\mathrm{sp}^{2}-\mathrm{C}$ generated during annealing towards water molecules as suggested by XAS experiments [54]. This oxygen can also result from the reaction of ambient oxygen with defective graphitic structures generated during annealing on the DND surface [25].

Still concerning the surface terminations, our study emphasizes the creation of $\mathrm{CH}_{x}$ aliphatic bounds when DND are treated under vacuum or argon, as evidenced by infrared spectroscopy. Such $\mathrm{CH}_{x}$ are not detected by FTIR for initial DND in the same analysis conditions. It must be underlined here that IR spectroscopy probes the whole nanoparticle; therefore, we cannot discriminate if $\mathrm{CH}_{x}$ are created on or within the DND. Whatever its location, the origin of this hydrogen must be discussed. The creation of $\mathrm{C}-\mathrm{H}$ bonds requires a hydrogen-rich atmosphere surrounding DND during the treatment or during the cooling down of the particles. We observed quite similar $\mathrm{C}-\mathrm{H}$ stretching signatures (location and relative intensities) for both atmospheres, while they have been performed in dynamic primary vacuum at $10^{-3}$ mbar or under atmospheric pressure with a flow of argon at $20 \mathrm{sccm}$. Therefore, hydrogen coming from the degradation of desorbed functions (hydroxyls, carboxyl) and remaining in the vicinity of the particle is unlikely to be the only origin of the phenomenon. The hypothesis of hydrogen coming from the DND would appear more realistic, as the presence of such trapped hydrogen in the DND core was revealed previously by isotopic studies [55]. Indeed, hydrogen content in the range of 4 to $10 \mathrm{mg} / \mathrm{g}$ was measured by elemental analysis in DND of different origins [56] and shown to be kept inside the particle up to $750{ }^{\circ} \mathrm{C}$ [18]. The exodiffusion of hydrogen from the DND core was strengthened by a previous TDMS study performed on annealed DND. Hydrogen release was detected starting at $800^{\circ} \mathrm{C}$ and raising up to $1000^{\circ} \mathrm{C}$ [57]. To resume, we suggest here that the annealing of DND (at least from $800^{\circ} \mathrm{C}$ ) is accompanied by a thermodesorption of hydrogen initially trapped in the core, which induces the creation of $\mathrm{CH}_{x}$ functions through a catalytic pathway already described elsewhere [58].

Nevertheless, we observed a modification of $\mathrm{C}-\mathrm{H}$ stretching bands according to the temperature treatment, which follows the same trend for primary vacuum and argon atmosphere. At $800{ }^{\circ} \mathrm{C}$, the C-H stretching modes look similar to those obtained after a $\mathrm{H}_{2}$ annealing or plasma treatment [59], with two intense peaks centered at 2945 and $2879 \mathrm{~cm}^{-1}$. The nanodiamond literature reports two possibilities to attribute these peaks. Cheng and coworkers attributed these 2945 and $2879 \mathrm{~cm}^{-1}$ peaks to $\mathrm{C}(110): \mathrm{H}$ and $\mathrm{C}(100): \mathrm{H}$, respectively, even on $5 \mathrm{~nm}$ detonation nanodiamonds [40]. In the meantime, several papers [60,61] since the pioneering one of Jiang et al. in 1996 [62] have described the doublet located at 2950 and $2871 \mathrm{~cm}^{-1}$ to the asymmetric and symmetric stretching vibrations of $\mathrm{CH}_{3}$ groups. Progressively, as the temperature of annealing raises, the 2922 and $2852 \mathrm{~cm}^{-1}$ bands become prominent, while the 2950 and $2871 \mathrm{~cm}^{-1}$ structures remain visible but less intense. This would mean a transition between $\mathrm{CH}_{3}$ to $\mathrm{CH}_{2}$ groups according to Jiang's papers, which should be driven by the annealing temperature and the concomitant reconstruction of the nanodiamond surface while isolated graphitic structures cover the particle. On the other hand, this evolution may also be due to an evolution of mean diameter of the particles probed, towards smaller sizes, if we consider the work of Cheng and coworkers. However, considering our HR-TEM observations, the diameters of annealed DND do not seem to be reduced, which rules out this hypothesis.

The infrared analysis puts also into light the apparition of a large band ranging from 1620 to $1550 \mathrm{~cm}^{-1}$ and centered around $1580 \mathrm{~cm}^{-1}$ with the annealing procedure, whatever the atmosphere. A part of this area $\left(1620-1590 \mathrm{~cm}^{-1}\right)$ can be attributed to red-shifted $\mathrm{OH}$ bending modes related to specific water interaction with hydrophobic surface, which could be the case here, as our DND surface seems to become hydrogenated and may exhibit some graphitic carbon at its surface $[39,63]$. However, this specific $\mathrm{OH}$ bending mode should be accompanied with an $\mathrm{OH}$ stretching mode between 3620 and $3690 \mathrm{~cm}^{-1}$ also specific to hydrophobic surfaces [38], which is not visible in our spectra. Furthermore, to check if adsorbed water could be responsible for that band, annealed DND were 
suspended in $\mathrm{D}_{2} \mathrm{O}$; this band was still detected (Figure S2) despite the expected isotopic shift of OD band. Therefore, despite hydrogen and $\mathrm{sp}^{2}$ carbon on their surface, our treated DND do not seem to exhibit clear hydrophobic behavior. Still in the same area, another contribution may concern vinyl $C=C$ bounds (around $1580 \mathrm{~cm}^{-1}$ ) [64,65]. However, if this band is related to $\mathrm{C}=\mathrm{C}$ bonds, and by extension to graphitic reconstructions, XPS data does not support the infrared analysis since this band at $1580 \mathrm{~cm}^{-1}$ is prominent for samples annealed under argon and weaker for those annealed under vacuum, while higher $\mathrm{sp}^{2}-\mathrm{C}$ content was evidenced on $\mathrm{C} 1 \mathrm{~s}$ core levels of vacuum annealed samples. In the meantime, quantification on infrared absorption spectrum remains hazardous.

Thermal treatments are expected to lead to the creation of graphitic carbon on DND. In this study, Raman spectroscopy was initially used to reveal this evolution of the $\mathrm{sp}^{3}$ carbon to $\mathrm{sp}^{2}$ carbon. Here, what is shown by Raman spectroscopy is mainly the loss of the first order diamond peak which is hidden by the $\mathrm{D}$ band, most related to disordered carbon. However, HR-TEM images performed on the same samples confirm that the diamond core is preserved, even for the highest temperature. Indeed, at this excitation wavelength of $532 \mathrm{~nm}$, the scattering of "graphitic" carbons (D and G bands) is exalted compared to diamond, by a factor of 50 [43]. This is a good illustration of the difficulty to use such green excitation to probe nanodiamond structure by Raman spectroscopy, especially when annealing treatments are considered [42].

XPS analysis provides a quantitative study of the graphitization. From $3.5 \%$ of the overall carbon probed on initial DND, this proportion of $\mathrm{sp}^{2}$-hybridized carbon went up to 15 and $30 \%$ for annealing performed under argon and vacuum, respectively. We observe with this technique the first noticeable difference induced by the atmosphere. Note that annealing temperatures over the experimental range $\left(800-950{ }^{\circ} \mathrm{C}\right)$ were checked in situ using an additional thermocouple, and comparable values were measured, whatever the atmosphere. In our study, vacuum annealing definitely induces more sp-hybridized carbon in this temperature range than the same treatment realized at atmospheric pressure under an inert atmosphere. The cause of this observation is most probably related to the reactivity of the carbon dangling bonds at low pressure. Now, if we look deeper in the values of created $\mathrm{sp}^{2}$-hybridized carbon provided by XPS, the maximum of $30 \%$ may suggest a thick graphic layer surrounding DND. However, HR-TEM images do not evidence such structures, revealing only very peripheral modifications of the DND, even at $950{ }^{\circ} \mathrm{C}$. This can be explained by a "nano" effect that should be taken into consideration in our XPS analysis. Due to geometrical consideration and when the radius of the particle approaches the inelastic mean free path of electrons $(\approx 2 \mathrm{~nm}$ in diamond [66]), well described by Baer and Engelhard [67,68], a 2.5-fold enhancement of the carbon signal coming from the first $0.5 \mathrm{~nm}$ of $\mathrm{a} \approx 5 \mathrm{~nm}$ nanoparticle occurs. Therefore, in our case, if we consider that $\mathrm{sp}^{2}$ carbon is located at the extreme surface of DND as seen in HR-TEM, this ratio of $30 \%$ can be reduced to $12 \%$, which roughly represents one layer of carbon atoms at the surface of $\mathrm{a} \approx 5 \mathrm{~nm}$ nanoparticle. The thickness of $\mathrm{sp}^{2}$ layer estimated from HR-TEM images is included between 0.45 and $0.58 \mathrm{~nm}$. This corrected amount of sp2-hybridized carbon is more in agreement with our HR-TEM observations, considering that for a $\approx 5 \mathrm{~nm}$ diamond particle, $15 \%$ of carbon atoms are located at the surface [69]. This observation was confirmed by an additional thermal treatment we performed under vacuum at $1100{ }^{\circ} \mathrm{C}$. On this sample, HR-TEM clearly exhibits the formation of more organized graphitic structures at the extreme surface of DND (Figure S3), but still limited to a monolayer. In agreement, $\mathrm{sp}^{2}$-hybridized carbon component of the $\mathrm{C} 1 \mathrm{~s}$ core level spectrum remains around 30\% (Figure S4). However, we noticed a down-shift of the $\mathrm{sp}^{2}$-hybridized carbon component with respect to the $\mathrm{sp}^{3} \mathrm{C}-\mathrm{C}$ diamond up to $-1.3 \mathrm{eV}$. This down-shift may reflect the higher degree of organization of this graphitic structure as seen on HR-TEM images. Note that this exaltation of the sp²-hybridized carbon also occurs for initial and low-temperature annealed DND. This means that less than $1 \%$ of $\mathrm{sp}^{2}$-hybridized is present on initial particles, in full agreement with HR-TEM images. 
XPS analysis provides complementary information about the crystalline structure of treated nanodiamonds. Initially, the component related to $\mathrm{sp}^{3} \mathrm{C}-\mathrm{C}$ neighboring structural defects, carbon partially saturated with hydrogen and carbon bounded to a nitrogen atom counts for more than half of the $\mathrm{C} 1 \mathrm{~s}$ total area (53\%). At the same time, the component relative to the $\mathrm{sp}^{3} \mathrm{C}-\mathrm{C}$ diamond type only represents $6 \%$ of the total carbon probed. After annealing at 800 or $850^{\circ} \mathrm{C}$, according to the atmosphere, a reorganization of the $\mathrm{C}-\mathrm{C} \mathrm{sp}{ }^{3}$ bonds seems to occur, as the latter component grows up to more than $40 \%$ of the C1s core level, while the former is notably reduced. It is well known in the field of NV (nitrogen vacancy) center synthesis that annealing above $750{ }^{\circ} \mathrm{C}$ leads to a migration of vacancies contained in the nanodiamond core to meet nitrogen atoms to form $\mathrm{NV}$ centers, while some vacancies are released to the surface [50]. The raise of the $\mathrm{sp}^{3} \mathrm{C}-\mathrm{C}$ diamond type component from 6 to $41 \%$ may be explained by this effect, i.e., due to the "healing" of the core defects. Such an effect was evidenced by electron paramagnetic resonance (EPR) with a reduced density of spins, by a factor of two, for DND annealed at $600{ }^{\circ} \mathrm{C}$ compared to initial particles [34]. This is assigned to a reduction of dangling bonds in the $\mathrm{sp}^{3}$ diamond core. At the same time, the second component initially linked to these defects is progressively replaced by the reconstructed surface, left by the desorption of the oxygen-related groups at the surface of the particle. Note that part of these evolutions may be exalted by the "nano effect" as explained above for superficial carbon bounds. In our experiments, we also noticed that $\mathrm{sp}^{3} \mathrm{C}-\mathrm{C}$ diamond component, related to the core of the DND, is reduced from 45 to $29 \%$ when high temperatures are reached, partly replaced by sp2-hybridized carbon component and $\mathrm{sp}^{3} \mathrm{C}-\mathrm{C}$ neighboring structural defects. In this temperature range, some carbon atoms from the diamond core underwent structural modifications, leading to more defects in the diamond lattice. The HR-TEM images of the additional experiments at $1100{ }^{\circ} \mathrm{C}$ in vacuum (Figure S3) illustrate this hybrid structure with a diamond core surrounded with defective layers and covered with a more organized $\mathrm{sp}^{2}$ layer, exhibiting a cubic symmetry as shown by the FFT presented on Figure S5).

\section{Conclusions}

An accurate control of the early stages of DND graphitization is desirable to further exploit the outstanding properties of the nanodiamonds in the fields of energy science and nanomedicine [16], or towards efficient functionalization [18]. In the present work, DND from Adamas Nanotechnology were annealed in the $800-950{ }^{\circ} \mathrm{C}$ range under two atmospheres in the same set-up: vacuum at $10^{-3}$ mbar or argon flow at atmospheric pressure. The effects of thermal treatments on DND surface chemistry, crystallinity, and carbon hybridization were investigated via complementary techniques (FTIR, Raman, XPS, and HR-TEM).

In the $800-950^{\circ} \mathrm{C}$ range, a very progressive formation of $\mathrm{sp}^{2}$-hybridized carbon was evidenced and quantified by XPS and appeared to be more efficient for DND annealed under vacuum (up to $30 \%$ of the total carbon) than under argon at atmospheric pressure. Taking into account the nano-effect reported in XPS for 5-6 nm particles [69], the highest $\mathrm{sp}^{2}$ amount obtained in this study corresponds to a monolayer, in fair agreement with the HR-TEM images. Therefore, by adjusting the temperature within this range of temperatures, we showed that it is possible to finely tune the DND surface chemistry into a hybrid structure presenting $\mathrm{sp}^{2}$ and $\mathrm{sp}^{3}$ carbons at its surface. Note that pushing the treatment up to $1100^{\circ} \mathrm{C}$ under vacuum does not increase the amount of $\mathrm{sp}^{2}$-hybridized carbon but gives rise to a better-organized aromatic structure. We also evidenced by XPS the "self-healing" of the defects initially present in the DND cores when they are exposed to $800{ }^{\circ} \mathrm{C}$ (or above). Another point of high interest revealed here is the systematic appearance of $\mathrm{C}-\mathrm{H}$ stretching bands in all annealed samples, whatever the atmosphere. The exodiffusion of hydrogen from the diamond core and the subsequent creation of aliphatic $\mathrm{C}-\mathrm{H}$ bonds are the most probable origins of this effect. 
In summary, our study provides a fine characterization of the early stages of graphitization of DND. Our results emphasize that within the $800-1100{ }^{\circ} \mathrm{C}$ range and for this source of nanodiamonds, it is possible to finely control the amount and the crystallinity of $\mathrm{sp}^{2}$-hybridized carbon at the periphery of DND mainly from the first outer-shell, while the coexistence of $\mathrm{C}-\mathrm{H}$ functions cannot be avoided. It may be of interest to investigate these early stages of graphitization on other DND sources to better define how these results are particle dependent.

Supplementary Materials: The following are available online at www.mdpi.com/article/10.3390/nano11102671/s1, Figure S1: Fitted XPS C1s core levels and associated values, Figure S2: FTIR of DND annealed at $800{ }^{\circ} \mathrm{C}$ suspended in $\mathrm{D}_{2} \mathrm{O}$, Figure S3: HR-TEM images of DND annealed at $1100{ }^{\circ} \mathrm{C}$ under vacuum, Figure S4: Fitted XPS C1s core level of DNDs annealed at $1100^{\circ} \mathrm{C}$ under vacuum and associated values, Figure S5: HR-TEM images and FFT for as received DND and DND annealed under vacuum at $950{ }^{\circ} \mathrm{C}$ and $1100{ }^{\circ} \mathrm{C}$.

Author Contributions: Conceptualization, H.A.G. and J.-C.A.; methodology, F.D., H.A.G. and J.-C.A.; validation, H.A.G. and J.-C.A.; formal analysis, F.D., H.A.G. and J.-C.A.; investigation, F.D., J.L., E.L. I.F., H.A.G. and J.-C.A.; resources, H.A.G. and J.-C.A.; data curation, F.D., H.A.G. and J.-C.A.; writing - original draft preparation, F.D., H.A.G. and J.-C.A.; writing - review and editing, F.D., H.A.G., J.L., E.L., I.F., E.B., C.S.-R. and J.-C.A.; visualization, F.D, H.A.G. and J.-C.A.; supervision, H.A.G. and J.-C.A.; project administration, H.A.G., E.B., C.S.-R. and J.-C.A.; funding acquisition, C.S.-R. and J.-C.A. All authors have read and agreed to the published version of the manuscript.

Funding: This research received no external funding.

Conflicts of Interest: The authors declare no conflict of interest.

\section{References}

1. Turcheniuk, K.; Mochalin, V.N. Biomedical applications of nanodiamond (Review). Nanotechnology 2017, 28, 252001, doi:10.1088/1361-6528/aa6ae4.

2. Navalón, S.; Dhakshinamoorthy, A.; Álvaro, M.; García, H. Diamond Nanoparticles in Heterogeneous Catalysis. Chem. Mater. 2020, 32, 4116-4143, doi:10.1021/acs.chemmater.0c00204.

3. Ivanov, M.; Shenderova, O. Nanodiamond-based nanolubricants for motor oils. Curr. Opin. Solid State Mater. Sci. 2017, 21, 17-24, doi:10.1016/j.cossms.2016.07.003.

4. Zhang, Y.; Rhee, K.Y.; Hui, D.; Park, S.J. A critical review of nanodiamond based nanocomposites: Synthesis, properties and applications. Compos. Part. B Eng. 2018, 143, 19-27, doi:10.1016/j.compositesb.2018.01.028.

5. Wang, H.; Lee, D.-K.; Chen, K.-Y.; Chen, J.-Y.; Zhang, K.; Silva, A.; Ho, C.-M.; Ho, D. Mechanism-Independent Optimization of Combinatorial Nanodiamond and Unmodified Drug Delivery Using a Phenotypically Driven Platform Technology. ACS Nano 2015, 9, 3332-3344, doi:10.1021/acsnano.5b00638.

6. Van der Laan, K.; Hasani, M.; Zheng, T.; Schirhagl, R. Nanodiamonds for In Vivo Applications. Small 2018, 14, 1-17, doi:10.1002/smll.201703838.

7. Choi, H.S.; Liu, W.; Misra, P.; Tanaka, E.; Zimmer, J.P.; Itty Ipe, B.; Bawendi, M.G.; Frangioni, J.V. Renal clearance of quantum dots. Nat. Biotechnol. 2007, 25, 1165-1170, doi:10.1038/nbt1340.

8. Claveau, S.; Nehlig, É.; Garcia-Argote, S.; Feuillastre, S.; Pieters, G.; Girard, H.A.; Arnault, J.-C.; Treussart, F.; Bertrand, J.-R. Delivery of siRNA to Ewing Sarcoma Tumor Xenografted on Mice, Using Hydrogenated Detonation Nanodiamonds: Treatment Efficacy and Tissue Distribution. Nanomaterials 2020, 10, 553, doi:10.3390/nano10030553.

9. Shvidchenko, A.V.; Eidelman, E.D.; Vul', A.Y.; Kuznetsov, N.M.; Stolyarova, D.Y.; Belousov, S.I.; Chvalun, S.N. Colloids of detonation nanodiamond particles for advanced applications. Adv. Colloid Interface Sci. 2019, 268, 64-81, doi:10.1016/j.cis.2019.03.008.

10. Mironova, E.Y.; Ermilova, M.M.; Efimov, M.N.; Zemtsov, L.M.; Orekhova, N.V.; Karpacheva, G.P.; Bondarenko, G.N.; Zhilyaeva, N.A.; Muraviev, D.N.; Yaroslavtsev, A.B. Detonation nanodiamonds as catalysts of steam reforming of ethanol. Russ. Chem. Bull. 2013, 62, 2317-2321, doi:10.1007/s11172-013-0336-2.

11. Zhang, L.; Hamers, R.J. Photocatalytic reduction of CO2 to CO by diamond nanoparticles. Diam. Relat. Mater. 2017, 78, 24-30, doi:10.1016/j.diamond.2017.07.005.

12. Mi, Z.; Chen, C.-B.; Tan, H.Q.; Dou, Y.; Yang, C.; Turaga, S.P.; Ren, M.; Vajandar, S.K.; Yuen, G.H.; Osipowicz, T.; et al. Quantifying nanodiamonds biodistribution in whole cells with correlative iono-nanoscopy. Nat. Commun. 2021, 12, 1-9, doi:10.1038/s41467-021-25004-9. 
13. Grall, R.; Girard, H.; Saad, L.; Petit, T.; Gesset, C.; Combis-Schlumberger, M.; Paget, V.; Delic, J.; Arnault, J.-C.; Chevillard, S. Impairing the radioresistance of cancer cells by hydrogenated nanodiamonds. Biomaterials 2015, 61, 290-298, http://dx.doi.org/10.1016/j.biomaterials.2015.05.034.

14. Brun, E.; Girard, H.A.; Arnault, J.; Mermoux, M.; Sicard-Roselli, C. Hydrogen plasma treated nanodiamonds lead to an overproduction of hydroxyl radicals and solvated electrons in solution under ionizing radiation. Carbon N. Y. 2020, 162, 510-518, doi:10.1016/j.carbon.2020.02.063.

15. Wehling, J.; Dringen, R.; Zare, R.N.; Maas, M.; Rezwan, K. Bactericidal activity of partially oxidized nanodiamonds. ACS Nano 2014, 8, 6475-6483, doi:10.1021/nn502230m.

16. Lin, Y.; Sun, X.; Su, D.S.; Centi, G.; Perathoner, S. Catalysis by hybrid $\mathrm{sp}^{2} / \mathrm{sp}^{3}$ nanodiamonds and their role in the design of advanced nanocarbon materials. Chem. Soc. Rev. 2018, 47, 8438-8473, doi:10.1039/c8cs00684a.

17. Yang, K.; Wan, J.; Zhang, S.; Tian, B.; Zhang, Y.; Liu, Z. The influence of surface chemistry and size of nanoscale graphene oxide on photothermal therapy of cancer using ultra-low laser power. Biomaterials 2012, 33, 2206-2214, doi:10.1016/j.biomaterials.2011.11.064.

18. Liang, Y.; Meinhardt, T.; Jarre, G.; Ozawa, M.; Vrdoljak, P.; Schöll, A.; Reinert, F.; Krueger, A. Deagglomeration and surface modification of thermally annealed nanoscale diamond. J. Colloid Interface Sci. 2011, 354, 23-30, doi:10.1016/j.jcis.2010.10.044.

19. Su, D.; Maksimova, N.I.; Mestl, G.; Kuznetsov, V.L.; Keller, V.; Schlögl, R.; Keller, N. Oxidative dehydrogenation of ethylbenzene to styrene over ultra-dispersed diamond and onion-like carbon. Carbon N. Y. 2007, 45, 2145-2151, doi:10.1016/j.carbon.2007.07.005.

20. Kuznetsov, V.L.; Butenko, Y.V. Diamond phase transitions at nanoscale. In Ultananocrystalline Diamond, 2nd ed.; Shenderova, O.A., Gruen, D.M., Eds.; Elsevier: Oxford, UK, 2012; pp. 181-244; ISBN 978-1-4377-3465-2.

21. Zeiger, M.; Jäckel, N.; Mochalin, V.N.; Presser, V. Review: Carbon onions for electrochemical energy storage. J. Mater. Chem. A 2016, 4, 3172-3196, doi:10.1039/C5TA08295A.

22. Mykhaylyk, O.O.; Solonin, Y.M.; Batchelder, D.N.; Brydson, R. Transformation of nanodiamond into carbon onions: A comparative study by high-resolution transmission electron microscopy, electron energy-loss spectroscopy, X-ray diffraction, small-angle X-ray scattering, and ultraviolet Raman spectroscopy. J. Appl. Phys. 2005, 97, 074302, doi:10.1063/1.1868054.

23. Zeiger, M.; Jäckel, N.; Aslan, M.; Weingarth, D.; Presser, V. Understanding structure and porosity of nanodiamond-derived carbon onions. Carbon N. Y. 2015, 84, 584-598, doi:10.1016/j.carbon.2014.12.050.

24. Plonska-Brzezinska, M.E.; Molina-Ontoria, A.; Echegoyen, L. Post-modification by low-temperature annealing of carbon nano-onions in the presence of carbohydrates. Carbon N. Y. 2014, 67, 304-317, doi:10.1016/j.carbon.2013.09.093.

25. Xie, F.Y.; Xie, W.G.; Gong, L.; Zhang, W.H.; Chen, S.H.; Zhang, Q.Z.; Chen, J. Surface characterization on graphitization of nanodiamond powder annealed in nitrogen ambient. Surf. Interface Anal. 2010, 42, 1514-1518, doi:10.1002/sia.3350.

26. Aleksenskii, A.E.; Baidakova, M.V.; Vul, A.Y.; Dideikin, A.T.; Siklitskii, V.I.; Vul', S.P. Effect of hydrogen on the structure of ultradisperse diamond. Phys. Solid State 2000, 42, 1575-1578, doi:10.1134/1.1307073.

27. Fugaciu, F.; Hermann, H.; Seifert, G. Concentric-shell fullerenes and diamond particles: A molecular-dynamics study. Phys. Rev. B 1999, 60, 10711-10714, doi:10.1103/PhysRevB.60.10711.

28. Kuznetsov, V.L.; Zilberberg, I.L.; Butenko, Y.V.; Chuvilin, A.L.; Segall, B. Theoretical study of the formation of closed curved graphite-like structures during annealing of diamond surface. J. Appl. Phys. 1999, 86, 863, doi:10.1063/1.370816.

29. Raty, J.-Y.; Galli, G.; Bostedt, C.; van Buuren, T.; Terminello, L. Quantum Confinement and Fullerenelike Surface Reconstructions in Nanodiamonds. Phys. Rev. Lett. 2003, 90, 1-4, doi:10.1103/PhysRevLett.90.037401.

30. Ray, M.A.; Shenderova, O.; Hook, W.; Martin, A.; Grishko, V.; Tyler, T.; Cunningham, G.B.; McGuire, G. Cold plasma functionalization of nanodiamond particles. Diam. Relat. Mater. 2006, 15, 1809-1812, doi:10.1016/j.diamond.2006.06.003.

31. Petit, T.; Arnault, J.C.; Girard, H.A.; Sennour, M.; Bergonzo, P. Early stages of surface graphitization on nanodiamond probed by X-ray photoelectron spectroscopy. Phys. Rev. B Condens. Matter Mater. Phys. 2011, 84, 233407, doi:10.1103/PhysRevB.84.233407.

32. Petit, T.; Arnault, J.-C.; Girard, H.A.; Sennour, M.; Kang, T.-Y.; Cheng, C.-L.; Bergonzo, P. Oxygen hole doping of nanodiamond. Nanoscale 2012, 4, 6792, doi:10.1039/c2nr31655b.

33. Cebik, J.; McDonough, J.K.; Peerally, F.; Medrano, R.; Neitzel, I.; Gogotsi, Y.; Osswald, S. Raman spectroscopy study of the nanodiamond-to-carbon onion transformation. Nanotechnology 2013, 24, 205703, doi:10.1088/0957-4484/24/20/205703.

34. Panich, A.M.; Shames, A.I.; Sergeev, N.A.; Olszewski, M.; McDonough, J.K.; Mochalin, V.N.; Gogotsi, Y. Nanodiamond graphitization: A magnetic resonance study. J. Phys. Condens. Matter 2013, 25, 245303, doi:10.1088/0953-8984/25/24/245303.

35. Koshcheev, A.P. Thermodesorption mass spectrometry in the light of solution of the problem of certification and unification of the surface properties of detonation nano-diamonds. Russ. J. Gen. Chem. 2009, 79, 2033-2044, doi:10.1134/S1070363209090357.

36. Petit, T.; Puskar, L. FTIR spectroscopy of nanodiamonds: Methods and interpretation. Diam. Relat. Mater. 2018, 89, 52-66, doi:10.1016/j.diamond.2018.08.005.

37. Ackermann, J.; Krueger, A. Efficient surface functionalization of detonation nanodiamond using ozone under ambient conditions. Nanoscale 2019, 11, 8012-8019, doi:10.1039/c9nr01716j.

38. Stehlik, S.; Glatzel, T.; Pichot, V.; Pawlak, R.; Meyer, E.; Spitzer, D.; Rezek, B. Water interaction with hydrogenated and oxidized detonation nanodiamonds-Microscopic and spectroscopic analyses. Diam. Relat. Mater. 2016, 63, 97-102, doi:http://dx.doi.org/10.1016/j.diamond.2015.08.016. 
39. Petit, T.; Puskar, L.; Dolenko, T.; Choudhury, S.; Ritter, E.; Burikov, S.; Laptinskiy, K.; Brzustowski, Q.; Schade, U.; Yuzawa, H.; et al. Unusual Water Hydrogen Bond Network around Hydrogenated Nanodiamonds. J. Phys. Chem. C 2017, 121, 5185-5194, doi:10.1021/acs.jpcc.7b00721.

40. Cheng, C.-L.; Chen, C.-F.; Shaio, W.-C.; Tsai, D.-S.; Chen, K.-H. The CH stretching features on diamonds of different origins. Diam. Relat. Mater. 2005, 14, 1455-1462, doi:10.1016/j.diamond.2005.03.003.

41. Aleksenskiľ, A.E.; Baǐdakova, M.V.; Vul, A.Y.; Davydov, V.Y.; Pevtsova, Y.A. Diamond-graphite phase transition in ultradisperse-diamond clusters. Phys. Solid State 1997, 39, 1007-1015, doi:10.1134/1.1129989.

42. Mermoux, M.; Crisci, A.; Petit, T.; Girard, H.A.; Arnault, J.-C. Surface Modifications of Detonation Nanodiamonds Probed by Multiwavelength Raman Spectroscopy. J. Phys. Chem. C 2014, 118, 23415-23425, doi:10.1021/jp507377z.

43. Knight, D.S.; White, W.B. Characterization of diamond films by Raman spectroscopy. J. Mater. Res. 1989, 4, 385-393, doi:10.1557/JMR.1989.0385.

44. Brenier, R.; Mugnier, J.; Mirica, E. XPS study of amorphous zirconium oxide films prepared by sol-gel. Appl. Surf. Sci. 1999, 143, 85-91, doi:10.1016/S0169-4332(98)00901-5.

45. Ozawa, M.; Inaguma, M.; Takahashi, M.; Kataoka, F.; Krüger, A.; Ōsawa, E. Preparation and Behavior of Brownish, Clear Nanodiamond Colloids. Adv. Mater. 2007, 19, 1201-1206, doi:10.1002/adma.200601452.

46. Dolmatov, V.Y. On elemental composition and crystal-chemical parameters of detonation nanodiamonds. J. Superhard Mater. 2009, 31, 158-164, doi:10.3103/S1063457609030022.

47. Arnault, J.C. X-ray Photoemission Spectroscopy applied to nanodiamonds: From surface chemistry to in situ reactivity. Diam. Relat. Mater. 2018, 84, 157-168, doi:10.1016/j.diamond.2018.03.015.

48. Stehlik, S.; Mermoux, M.; Schummer, B.; Vanek, O.; Kolarova, K.; Stenclova, P.; Vlk, A.; Ledinsky, M.; Pfeifer, R.; Romanyuk, O.; et al. Size effects on surface chemistry and Raman spectra of Sub-5 nm oxidized high-pressure high-temperature and detonation nanodiamonds. J. Phys. Chem. C 2021, 125, 5647-5669, doi:10.1021/acs.jpcc.0c09190.

49. Girard, H.; Simon, N.; Ballutaud, D.; Herlem, M.; Etcheberry, A. Effect of anodic and cathodic treatments on the charge transfer of boron doped diamond electrodes. Diam. Relat. Mater. 2007, 16, 316-325, doi:10.1016/j.diamond.2006.06.009.

50. Smith, J.M.; Meynell, S.A.; Bleszynski Jayich, A.C.; Meijer, J. Colour centre generation in diamond for quantum technologies. Nanophotonics 2019, 8, 1889-1906, doi:10.1515/nanoph-2019-0196.

51. Turner, S.; Lebedev, O.I.; Shenderova, O.; Vlasov, I.I.; Verbeeck, J.; Van Tendeloo, G. Determination of Size, Morphology, and Nitrogen Impurity Location in Treated Detonation Nanodiamond by Transmission Electron Microscopy. Adv. Funct. Mater. 2009, 19, 2116-2124, doi:10.1002/adfm.200801872.

52. Figueiredo, J.L.; Pereira, M.F.R.; Freitas, M.M.A.; Órfão, J.J.M. Modification of the surface chemistry of activated carbons. Carbon N. Y. 1999, 37, 1379-1389, doi:10.1016/S0008-6223(98)00333-9.

53. Laikhtman, A.; Lafosse, A.; Le Coat, Y.; Azria, R.; Hoffman, A. Interaction of water vapor with bare and hydrogenated diamond film surfaces. Surf. Sci. 2004, 551, 99-105, doi:10.1016/j.susc.2003.12.015.

54. Petit, T.; Pflüger, M.; Tolksdorf, D.; Xiao, J.; Aziz, E.F. Valence holes observed in nanodiamonds dispersed in water. Nanoscale 2015, 7, 2987-2991, doi:10.1039/C4NR06639A.

55. Nehlig, E.; Garcia-Argote, S.; Feuillastre, S.; Moskura, M.; Charpentier, T.; Schleguel, M.; Girard, H.A.; Arnault, J.-C.; Pieters, G. Using hydrogen isotope incorporation as a tool to unravel the surfaces of hydrogen-treated nanodiamonds. Nanoscale 2019, 11, 8027-8036, doi:10.1039/C9NR01555H.

56. Mitev, D.P.; Townsend, A.T.; Paull, B.; Nesterenko, P.N. Microwave-assisted purification of detonation nanodiamond. Diam. Relat. Mater. 2014, 48, 37-46, doi:10.1016/j.diamond.2014.06.007.

57. Arnault, J.C.; Petit, T.; Girard, H.A.; Gesset, C.; Combis-Schlumberger, M.; Sennour, M.; Koscheev, A.; Khomich, A.A.; Vlasov, I.; Shenderova, O. Surface graphitization of ozone treated detonation nanodiamonds. Phys. Status Solidi Appl. Mater. Sci. 2014, 211, 2739-2743, doi:10.1002/pssa.201431397.

58. Ahmed, A.-I.; Mandal, S.; Gines, L.; Williams, O.A.; Cheng, C.-L. Low temperature catalytic reactivity of nanodiamond in molecular hydrogen. Carbon N. Y. 2016, 110, 438-442, doi:10.1016/j.carbon.2016.09.019.

59. Thalassinos, G.; Stacey, A.; Dontschuk, N.; Murdoch, B.J.; Mayes, E.; Girard, H.A.; Abdullahi, I.M.; Thomsen, L.; Tadich, A.; Arnault, J.; et al. Fluorescence and Physico-Chemical Properties of Hydrogenated Detonation Nanodiamonds. C J. Carbon Res. 2020, 6, 7, doi:10.3390/c6010007.

60. Shenderova, O.; Panich, A.M.; Moseenkov, S.; Hens, S.C.; Kuznetsov, V.; Vieth, H.-M. Hydroxylated Detonation Nanodiamond: FTIR, XPS, and NMR Studies. J. Phys. Chem. C 2011, 115, 19005-19011, doi:10.1021/jp205389m.

61. Williams, O.A.; Hees, J.; Dieker, C.; Jäger, W.; Kirste, L.; Nebel, C.E. Size-Dependent Reactivity of Diamond Nanoparticles. ACS Nano 2010, 4, 4824-4830, doi:10.1021/nn100748k.

62. Jiang, T.; Xu, K.; Ji, S.; Jib, S. FTIR studies on the spectral changes of the surface functional groups of ultradispersed diamond powder synthesized by explosive detonation after treatment in hydrogen, nitrogen, methane and air at different temperatures. J. Chem. Soc. Faraday Trans. 1996, 92, 3401-3406, doi:10.1039/FT9969203401.

63. Stehlik, S.; Henych, J.; Stenclova, P.; Kral, R.; Zemenova, P.; Pangrac, J.; Vanek, O.; Kromka, A.; Rezek, B. Size and nitrogen inhomogeneity in detonation and laser synthesized primary nanodiamond particles revealed via salt-assisted deaggregation. Carbon 2021, 171, 230-239, doi:10.1016/j.carbon.2020.09.026.

64. Scholz, J.; McQuillan, A.J.; Holt, K.B. Redox transformations at nanodiamond surfaces revealed by in situ infrared spectroscopy. Chem. Commun. 2011, 47, 12140-12142, doi:10.1039/c1cc14961j. 
65. Liang, Y.; Ozawa, M.; Krueger, A. A General Procedure to Functionalize Agglomerating Nanoparticles Demonstrated on Nanodiamond. ACS Nano 2009, 3, 2288-2296, doi:10.1021/nn900339s.

66. Tanuma, S.; Powell, C.J.; Penn, D.R. Calculations of electron inelastic mean free paths. IX. Data for 41 elemental solids over the $50 \mathrm{eV}$ to $30 \mathrm{keV}$ range. Surf. Interface Anal. 2011, 43, 689-713, doi:10.1002/sia.3522.

67. Baer, D.; Engelhard, M.; Gaspar, D. Challenges in Applying Surface Analysis Methods to Nanoparticles and Nanostructured Materials. J. Surf. Anal. 2005, 12, 101-108.

68. Baer, D.R.; Engelhard, M.H. XPS analysis of nanostructured materials and biological surfaces. J. Electron. Spectros. Relat. Phenom. 2010, 178-179, 415-432, doi:10.1016/j.elspec.2009.09.003.

69. Shenderova, O.A.; McGuire, G.E. Science and engineering of nanodiamond particle surfaces for biological applications (Review). Biointerphases 2015, 10, 030802, doi:10.1116/1.4927679. 